\title{
ENERGIA E DESENVOLVIMENTO *
}

Jurandir Antonio Xavier $\star \star$

\section{DESENVOLVIMENTO E SUBDESENVOLVIMENTO}

Neste ensaio pretende-se abordar a questão energética na sua dimensão econômica-histórica. Este enfoque é tanto mais justificado quan to mais essa temática esteja vinculada aos problemas do desenvolvimento.

Evitando entrar nos estudos das rendas per capita dos países desenvolvidos e subdesenvolvidos (ou em desenvolvimento, como nos últimos tempos passou-se a denominá-los) para caracterizar os possiveis niveis de desenvolvimento econômico, preferimos optar por uma conceituação menos fantasiosa, porém mais rigorosa no campo econômico, ancrada na economia no tempo do trabalho. $\mathrm{Na}$ realidade, o subdesenvolvimento é caracterizado, em última instância, pelo subemprego dos recursos humanos em uma sociedade: em uma dimensáo quantitativa, pelo desemprego em massa; em uma dimensăo qualitativa, pela baixa produtividade do trabalho. Claro está que estas dimensōes são relativas, ou seja, comparáveis aos n:́veis dados do desenvolvimento (Pleno emprego da força de trabalho ao mais elevado nível da produtividade social do trabalho). Estes níveis, como se sabe, são ilimitados, se considerados numa perspectiva histórica.

\section{OS CICLOS “CLĀSSICOS” DA ACUMULAÇÃO CAPITALISTA}

Nos estudos a longo prazo do comportamento geral de uma economia, existem alguns momentos peculiares que se repetem com relativa periodicidade. Os economistas procuram determiná-los invariavelmente com a maior rigorosidade que lhes permitem o instrumental analítico e os dados sócio-econômicos disponiveis. São os investimentos na renovação das máquinas e equipamentos empregados na produção social de bens. $O$ que conhecemos como custos de amortização dos capitais, incluídos nos preços

\footnotetext{
- Texto de palestra apresentada no encontro "Necessidádes Energéticas, Necessidades do Desenvolvimento". Centro Josué de Castro Recife, 10 de setembro de 1980 .

* Profascar do Depertamento de Economia a Financas e Coordenador do Núcleo do Ensino o Pasquisa om Polltica Cientlfica e Tecnológica (NENPPO), da Univorsidado Foderal de Paraßba. Campus II - Campina Grande.

\begin{tabular}{|l|l|l|l|l|l|}
\hline Rev. RAIZES & Campina Grande & Ano I & $N^{0} l$ & pgs. 157 - 163 & jul. - dez./ 1982 \\
\hline
\end{tabular}
}


de venda das mercadorias, constituem uma acumulaçăo na forma de fundos necessários para a substituiçáo dos capitais fixos nos prazos correspondentes de obsoletismo.

Estes momentos são decisivos para o aumento geral das atividades econômicas em uma sociedade capitalista. Eles caracterizam a alta conjuntura das atividades das indústrias produtoras de máquinas e equipamentos. Induzem também os demais ramos de produçáo (por exemplo, as indústrias de bens de consumo duráveis ou não duráveis) a uma reativaçāo geral de suas atividades (elevação do poder aquisitivo global resultante da elevada demanda de força de trabalho por parte do conjun to das empresas).

Desta forma, estes momentos de reconstituiç̧ão dos capitais fixos, momentos estes ocasionados ciclicamente, representam uma ampliaçăo das bases materiais e humanas da produção social de bens, colocando-as em niveis quantitativos superiores a cada novo ciclo da produção. Resumindo: os chamados momentos de reconstituição dos capitais fixos representam simultaneamente: elevaçáo quantitativa tanto das bases materiais como das bases humanas da produção.

Por outro lado, não há dúvidas de que ocorrem mudanças qualitativas nos processos de produção. De fato, estas ocorrem diariamente no interior das empresas. Deve-se, entretanto, destacar a significação da chamada "ampliação normal" das bases da produção nestes períodos. Nesta ampliação, a componente quantitativa sobrepassaria à componente qualitativa.

Calcula-se que a periodicidade destes fenômenos concomitantes para as economias ocidentais desenvolvidas no período que vai desde a Revolução Industrial até aproximadamente a segunda Guerra Mundial, variaram em torno de onze anos (mais exatamente entre dez e doze anos). Desde então, verifica-se uma aceleração das inovações tecnológicas, que, provocando um envelhecimento prematuro (obsoletismo moral na linguagem dos economistas) dos bens de produção, vem reduzindo o ciclo de periodicidade para cinco ou seis anos.

\section{OS LONGOS CICLOS DA ACUMULAÇĀO CAPITALISTA}

Por outro lado, hoje já sabemos que o processo de ampliaçăo da pro. dução, do crescimento econômico e das riquezas das nações nāo ocorre somente em ciclos "normais". Ainda é recente em nossas memórias a fabulosa expansão econômica dos países europeus do ocidente e, sobretudo dos Estados Unidos, no período que se seguiu à segunda Guerra Mundial. Quase todos estes países tiveram seu "milagre econômico". Esses perfodos prolongados de crescimento econômico, também denominados de longos 
ciclos da acumulação capitalista, seriam, em última análise, o resultado de uma sucessão dos ciclos antes caracterizados de "clássicos", compostos, como os demais, de uma fase de crescimento acelerado e outra de crescimento retardado.

Se auge e prosperidade dos ciclos normais da acumulação do capital estão identificados com a reconstituição e extensão quantitativa das bases técnicas e humanas da produção, o início e a fase expansiva dos longos ciclos de desenvolvimento econômico estão identificados, na sua componente técnica, com as transformaçōes revolucionárias, as chamadas Revoluçōes Tecnológicas, ocorridas nas bases materiais e humanas da produção social de uma economia. São os períodos e as fases de reconstituições colossais nas bases técnicas e econômicas da produção. É a reprodução ampliada da produção social em uma dime:são quantitativa: expansão da produção corrente e, provocada pela revolução tecnológica, expansão da produção mediante a criação de novos setores de produção até então inexistentes. E em uma dimensão qualitativa, a Revolução Tecnológica representa:mudan. ça no conjunto das máquinas, equipamentos, técnicas e métodos da produçăo e do trabalho. Portanto, elevação da produtividade social do trabalho.

Talvez fnsse desnecessário acrescentar que estes períodos de transformações são tanto mais transparentes, susceptíveis de previsōes e mesmo de planejamentos em suas dimensōes, quantio menos o processo da produção estiver condicionado exogenamente, exposto a repentinas, incontroláveis e arbitrárias variáveis intemacionais. Decisiva, para estes períodos sobretudo, é a convergência dos valores gerados na economia para a acumulação à medida em que condiciona as dimensões das transformaçðes.

Por fim, dimensionar o desenvol vimento econômico significaria dimensionar estas transformações ampliadas das bases materiais e humanas da produçāo social de bens quantitativamente e qualitativamente .

\section{A ENERGIA NA HISTÓRIA DA ACUMULAÇĀO CAPIT ALISTA}

Estas considerações anteriores foram necessárias para incorporar a questão energética ao plano histórico do desenvolvimento. $O$ que foi citado anteriormente como Revolução Tecnológica tem suas raízes técnicas nas mudanças ocorridas na área da energia.

São as transformaçōes técnicas na área da energia, na área da produçăo energética, que abrem as condiçōes e possibilidades técnicas para as mudanças substituiçōes e ampliações do conjunto das máquinas, equipamentos, técnicas e métodos de trabalho. Com elas, abrem-se, para alguns períodos sucessivos, as fronteiras de um longo ciclo de desenvolvimento econômico, abs- 
traindo-se, evidentemente, as determinaçōes sócio-econômicas deste novo longo ciclo.

Olhando em retrospectiva, a origem histórica da Revolução Industrial e do processo de industrialização nos países da Europa Ocidental está associada a substituição dos moinhos de água e de vento, (usados milenarmente na agricultura, na nascente produção artesanal e, posteriormente, na produçāo industrial manufatureira) pelas máquinas a vapor. Ou seja, pela introduç̧āo da energia térmica na produção social de bens.

Durante aproximadamente um século, até o final do século passado, o conjunto das máquinas e equipamentos empregados na produção eram movidos pela energia térmica, obtida a partir da queima do carvão mineral ou vegetal. Neste século, o desenvolvimento econòmico dos países em industrialização conhece dois perfodos de prolongada acumulação acelerada de capitais.

O primeiro, inicia-se com a própria Revolução Industrial e estende-se até o ano-chave de 1825. Foi o período de incorporação das novas máquinas e técnicas na produção de bens de consumo. (Textil, calçados, etc.). Estas máquinas, porém, eram ainda confeccionadas em grandes ma. nufaturas, ou seja artesanalmente.

Após o peŕodo de acumulação retardada, determinado pela "sat liraçăo" da demanda para esses tipos de equipamentos, abre-se, a partir de 1848, um novo período de acelerada acumulação que estende-se atć 1873. A acumulação caracterizou-se pelo surgimento da produçāo industrial em grande escala dos motores e máquinas térmicas. Com a introdução das máquinas térmicas na própria fabricação de máquinas, o nivel médio da produtividade do trabalho elevou-se em dimensões até entāo jamais imaginadas. De 1874 a 1893 os paises industrializados conheceram novamente um periodo de acumulação retardada de capitais. Tanto as indústrias de bens de consumo, como as indústrias de bens de produção já estavam sendo movidas pelas técnicas e máquinas térmicas.

0 terceiro longo período de expansáo quantitativa e qualitativa das bases materiais e humanas da produção social abre-se em torno de 1894, prolongando-se até a segunda Guerra Mundial. As condiçōes técnicas para a renovação e a ampliaçăo do conjunto do "stock" maquinário até entāo acumulado foram fornecidas pelas transformaçōes, uma vez mais, na área das técnicas de energia e das máquinas energéticas: os motores elétricos e os motores a explosão. Aqui já podemos fazer um a idéia mais concreta daquilo que foi descrito anteriormente como Revolução Tecnológica e suas conseqüências para a ampliação das riquezas das nações participantes nas origens mesmas destes processos inovativos. Basta lembrar os ramos de produção 
desses novos motores e das novas máquinas movidas a eletricidade e a petróleo, o ramo da produção automobilística, da produção de eletrodomésticos, a própria eletrificação, etc., para ter-se uma dimensão do duplo senti. do inerente ao desenvol vimento econòmico: elevaçăo quan titativa do emprego dos recursos humanos via extensão da produção social e elevação qualitativa do emprego dos recursos humanos disponiveis em uma sociedade via elevafão da produtividade social média do trabalho.

Já o quarto e último longo período de crescimento econômico acelerado nas econornias capitalistas avançadas, abre-se para o Estados Unidos em 1940, e para os paises da Europa Ocidental inicia-se com o pós-guerra. As bases técnicas para o desenvolvimento expansivo do quarto perioció foram colocadas pelas transformaçōes na área da eletrōnica, da petroqurmica e da energia nuclear. A utilização produtiva destas novas técnicas começa nas indústrias químicas, extendendo-se para os diversos ramos da produçāo, novos e antigos. Em 1954, inicia-se, nos setores privacios da economia, a utilização das técnicas e máquinas de processamento de dados. Nesta época, inicia-se igualmente a construçăo das usinas nucleares para uso "pacífico". Em torno deste ano, considera-se por encernada a fase de reconstrução do pós-guerra na Europa Ocidental e Japāo, iniciando-se a Era da Automação da produção social. O pleno emprego é atingido na maioria dos países industrializados e a produtividade do trabalho, em alguns ramos, tende ao "infinito". (Produção energética, Petroquimica, etc.).

Olhando em perspeciiva, os paises que viveram estas Revoluçōes Tecnológicas ativamente, isto é os países hoje conhecidos como desenvolvidos, encontram-se na encruzilhada. Não sem perspectivas, entretanto. Como é característico dos longos periodcs de acumulação retardada, as crises ou recessōes económicas se avolumam no tempo e seus períodos "normais" de ocorrência diminuem, exigindo e impuisionando novas transformaçōes radicais no conjunto das relações sócioeconômicas e, por último, nas técnicas da produção. Isso porque o conjunto das condições de produção exigem transformaçōes de toda ordem.

Abstraindo-se uma vez mais o conjunto das pré-condições sócioeconômicas para as possiveis alternativas no desdobramento de um longo período de acumulação, o quinto na história do capitalismo, verifica-se que os prenúncios deste novo longo periodo de expansão da produção social de mercadorias já se anuncia. A construção das usinas nucleares, interrompida em sua expansão vertiginosa pela avalanche de resistências róciopolíticas vão determinar os alcances da Revolução Tecnológica na área econômica. Aceleram-se, pois, as experiências para a produção e utilização em escala industrial da energia térmica provenitnte da fusão hidrogêni 
ca. Tanto os Estados Unidos, como os paises da Comunidade Econômica Européia, já investem bilhões nesta fonte energética. Será com esta base técnica que os paises desenvolvidos arrancarão para um novo longo perfodo de expansão econômica?

\section{UMA OUTRA VARIANTE}

$\mathrm{O}$ exposto até aqui nos dá uma dimensão do alcance histórico do papel da energia e das transformaçōes energéticas no desenvolvimento econômico dos paises mais avançados. Propositadamente e conscientemente foram excluídas aqui as consideraçōes sócio econômicas e políticas quando da determinação dos ciclos de crescimento económico. Foram exclurdos aqui os jogos com as cifras de custos ou estatísticas e também não foi considerada a questão energética nos paises subdesenvolvidos, ou em vías de desenvolvimento. Resumindo: pretendeu-se dar apenas o significado e o alcance histórico das transforaçōes energéticas, quando ocorridas na produção. Pretendeu-se mostrar, portanto, que as relações entre as transformaçōes na área da energia e o desenvolvimento econômico só podem ser consideradas desde e com uma perspectiva histórica, dado o longo alcance e os profundos efeitos destas relaçōes.

Em outras palavras: planejamento na área energética não se faz sob a ótica da conjuntura, como ocorre habitualmente neste pals. Sob a ótica conjuntural, não se planeja a produçáo de energia e muito menos o desenvolvimento, nem mesmo onde ele já existe e, com muito mais razão, nos pafses onde o subdesenvolvimento relativo aprofunda-se em forma acelerada.

Pnde-se considerar, no entanto, os problemas energéticos no Brasil sob o prisma conjuntural. Falar-se-á entāo de preços relativos. Por exemplo, em que conjuntura de preços para o petróleo proveniente das Arábias, a exploração do carvão vegetal da Amazônia ou o xisto betuminoso de tal ou qual região será rentável. Ou então, em que condições a utilização do álcool será mais rentável que a do petróleo para movimentar o absurdo transporte rodoviário de cargas de longa distância, como o existente no Brasil. No final, depois de se remediar com uma série de inracionalidades, poderse-á, talvez, apontar para uma possível conclusão, tida como sob menos irracional.

Colocar os problemas energéticos em uma dimensão histórica, é colocar em discussão, em primeiro lugar, as possibilidades, os caminhos, as condiçðes sócioeconômicas e políticas a serem contrapostos às tendências de aprofundamento do subdesenvolvimento relativo, atuantes no passado e profundas no presente da economia brasileira. Neste contexto, poder-se-á inserir os 
enormes efeitos desenvolvimentistas desencadeados pelas transformaçōes técnico-conômicas na área da produçâo energética.

Olhar em retrospectiva a atuaçáo governamental na história energética do Brasil é um tanto desalentador. O monopólio da extração do petróleo pela Petrobrás surge nos anos cinqüenta deste século, quando a produção de petróleo nos países industrializados já estava monopolizada desde o final do século passado. A Petrobrás, mesmo assim, nāo nasceu de planejamentos governamentais, nem de curto, nem de médio nem de longo prazo, senão como resultante das lutas sociais e políticas, principalmente do estudantado daquela época. Nos tempos atuais, como todos sabemos, a Petrobrás está sob ameaça de extinçao, via associação aos capitais estrangeiros.

A energia nuclear no Brasil já era ensaiada nos laboratórios de algumas universidades do Rio de Janeiro e Säo Paulo, desde o começo dos anos cinqüenta. Os pioneiros de então foram expulsos das universidades e mesmo do país. Como se sabe, o "pacote" nuclear neste país surge bionicamente, vindo das planícies germânicas, e continua inatingivel, ainda que quase unanimemente condenado, pelo menos para aqueles que não participam de seus frutos imediatos.

O Proálcool, por sua vez, poderá limitar as plantações e elevar os preços do feijāo, mandioca, batata, etc., apesar de movimentar alguns milhões de automóveis e saturar um ar já poluido.

Se estes são alguns dos planos principais para a área, resta lembrar que - Ministério de Minas e Energia, o Conselho Nacional de Energia (vinculado à Vice-Presidência da República), a Petrobrás, entre outros e outras, planejam "energia e desenvolvimento" neste pais. Porém a maior parte do tempo todos esses órgãos estāo em permanente conflito.

Concluindo: os fenômenos na área energética, não somente pelos bilhōes ou trilhōes que eles movimentam, mas, sobretudo, pela dimensão histórica dos efeitos que podem prvocar no desenvolvimento económico do país, não poderiam estar a margem de longas, profundas e fecundas discussões e decisões democráticas. Caso contrário, não se pretenderá falar com fundamento sobre desenvol vimento econömico. 